\title{
CAD based modeling of flywheel motor with multiple operator
}

\author{
Prasad Hatwalne ${ }^{1}$, Abhay Pitale ${ }^{2}$, Ranjan waghchore ${ }^{3}$, Mansoor Noor ${ }^{4}$ \\ ${ }_{1,2}$ (Department of Mechanical Engineering, PRMIT\&R Badnera, India) \\ 3,4 (Department of Mechanical Engineering, JDIET Yavatmal, India)
}

\begin{abstract}
The Human powered flywheel motor (HPFM) is the integral part of the various manually energized machines such as brick making machine, chaff cutter, pedal operated flour mill etc . Since its invention continuous efforts are being made for its optimization with objective of the efficient energy utilization of human energy. In an attempt this paper presents the development of flywheel motor for multiple rider as till now only single rider system is developed. Further the CAD modeling of this system is developed by using the CAD software SOLID EGDE.

Keywords - CAD modeling, HPFM, Solid edge.
\end{abstract}

\section{INTRODUCTION}

The ever increasing energy demand, unemployment in developing countries like India, Increased awareness of people towards the health are some of the driving forces for the development of humanly powered machines. These machines includes manually powered brick making machine, chaff cutter, pedal operated flour mill etc.

During 1979-99, Modak J.P. developed a human powered brick making machine for the manufacturing of bricks (Modak J.P. J.P. 1982, 1994, 1997, 1998) [1]. And since then various processes are energized by the human power such as wood turning, cloth washing, chaff cutter [2], potter"s wheel, flour mill etc. All these machines are operated by the human power with one common mechanism among them- The Flywheel Motor.

Flywheel motor is a mechanical system used to store the human energy and subsequently use it drive the respective process. The Machine consists of flywheel motor, driven bicycle mechanism with speed increasing gearing, which drives the shaft of process of process unit through clutch and torque amplification unit (Gupta 1977)[1].

Since invention the constants efforts are being continuously made to optimize the various parameters of these machines so as to provide the ease for the operator and consequently make efficient use of human energy. Hence in attempt the present paper proposes the modification of HPFM with multiple rider which haven't been done so far.

Further the CAD based modeling of the system using SOILD edge is done. This CAD model can be used for the various purposes such as simulation various analysis such as stress analysis, ergonomic analysis etc.

\section{FLYWHEEL MOTOR- THE CONCEPT.}

Any machine, to power it by human energy, the maximum power requirement should be 75 Watts. Any machine or process requiring more than 75 Watts and if process is intermittent without affecting and product, can also be operated by human energy

(Alexandrove 1981)[3]. This is possible with the provision of intermediate energy storing unit which stores the energy of human and supply periodically at required rate to process unit, this is called as "human powered flywheel motor."

Essentially the flywheel motor consists of flywheel, which is being driven by a human through a simple bicycle mechanism and pair of speed increasing gears[3]. The schematic of flywheel motor is as shown in Fig1. 


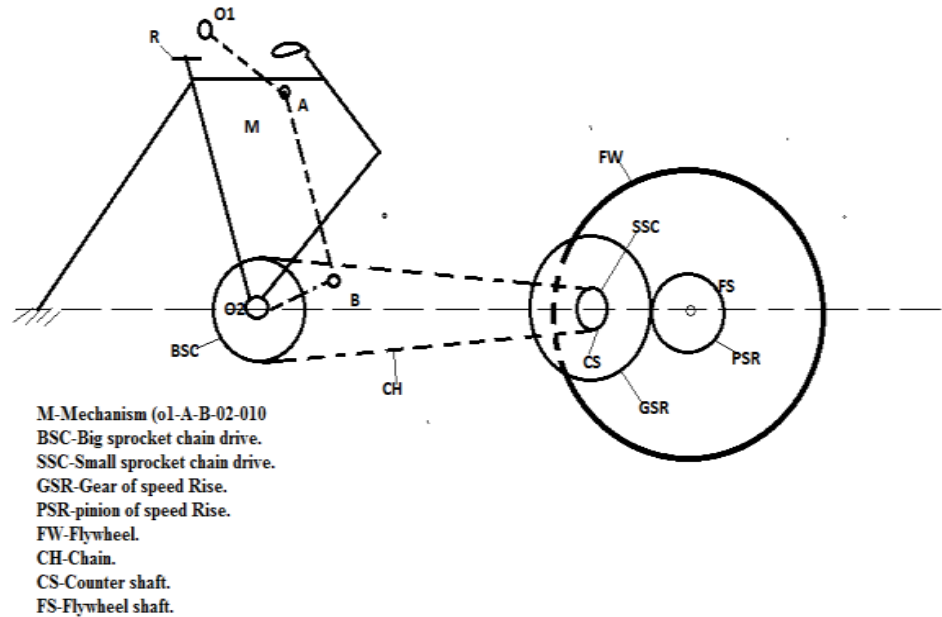

Fig1-Schematics of flywheel motor.

A rider pedals the mechanism , $\mathrm{M}^{\text {ee }}$ converting the oscillatory motion of thighs into rotational motion of counter shaft ", $\mathrm{C}^{\mathrm{ee}}$. This countershaft „ „C" connected to flywheel shaft „F $\mathrm{FS}^{\text {ee }}$ with speed increasing transmission consisting of pair of speed gears [4].Driver pumps the energy in flywheel at energy rate convenient to him [4]. In this way, the muscular energy of human is converted into kinetic energy of flywheel by this man machine and for its efficient use it is necessary to optimize its parameters[4].

\section{MODIFIED SYSTEM WITH MULTIPLE OPERATORS.}

As stated earlier the HPFM with multiple rider is developed. Which consists of two bicycle mechanism mounted on the both sides of common shaft. The 4 step gear box is used for the speed variation on the output shaft of which the flywheel is mounted. The schematics of this modified system is as shown in Fig2

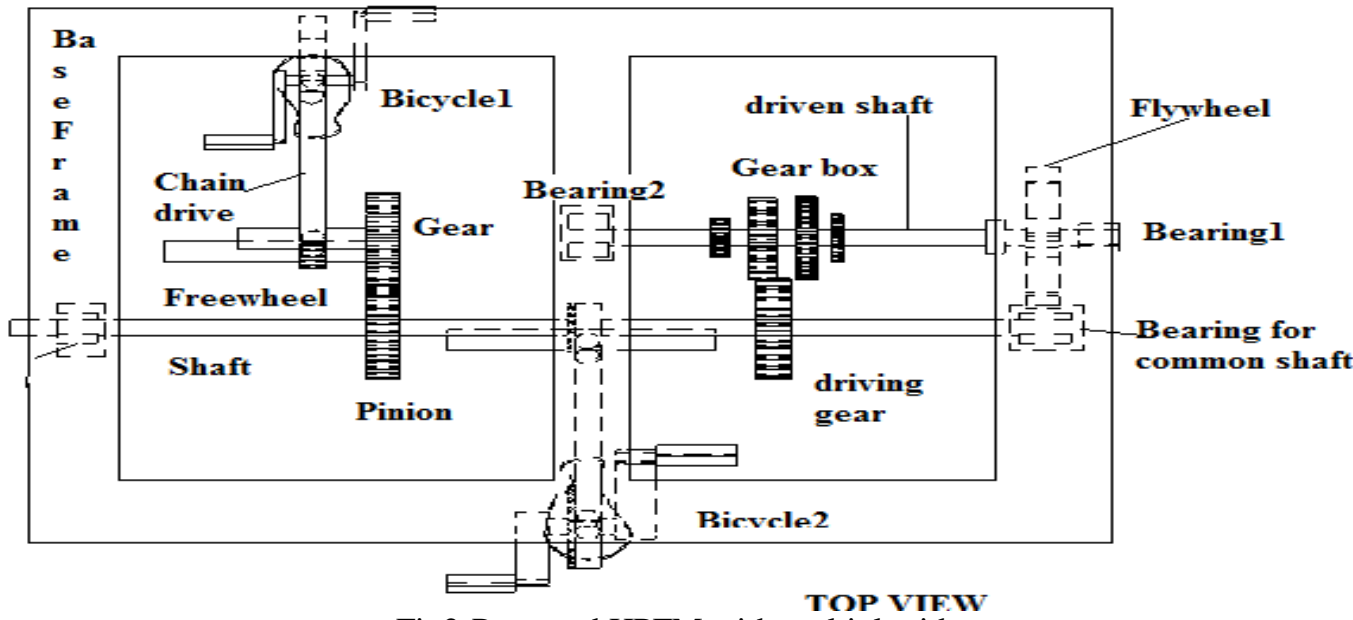

Fig2-Proposed HPFM with multiple rider

\section{DESIGN CONSIDERATIONS.}

At the beginning ,the flywheel motor was not based on any design data, rather it was built only on the intitution of human[4]. Later with the numerous experimentation the design data is made available which is discussed below.

\subsection{Modification in existing bicycle mechanism.}

Modak J.P (1985) has established the relationship between the useful torque developed at the crank as function of crank position during its revolution[5]. Modak J.P. also observed that out of $360^{\circ}$ rotation of pedal crank, only from $30^{\circ}-115^{\circ}$ of crank position from top dead center is useful. The rest of the period of crank position i.e. $0^{\circ}-30^{\circ}$ and $115^{\circ}-162^{\circ}$ is not effectively used and from $162^{\circ}-360^{\circ}$ is completely idle. Even when both the cranks are considered the useful driving angle is found to be $154^{\circ}$.[5]. Consequently for maximum utilization of operators energy Modak J.P. suggested three modified mechanisms namely Quick return ratio one, Double lever inversion and Elliptical sprocket[5].Based on his mathematical modeling he concluded improvement of $17 \%, 38 \%$, and $18 \%$ in human energy utilization for Quick return ratio one, Double lever 
inversion and Elliptical sprocket respectively. This performance of various bicycle drives then was experimentally verified by Modak J.P. , Chandurkar K.C. et,al (1987) and found almost matching with theoretical values[6].

\subsection{Flywheel speed and Moment of inertia.}

Modak J.P(1987) during the experimentation has ob-served the maximum thigh oscillation for the average person of $165 \mathrm{~cm}$ stature from age group 20-22 years is 40. [7]. With the available chain drive for existing 22" bicycle frame the flywheel speed of $240 \mathrm{rpm}$ was fair enough from point of total speed rise from pedals to flywheel shaft [7]. Further with calculation Modak J.P.(1987) has deter-mined the size of flywheel with the objective to store the maximum energy irrespective of speed fluctuations(180-240 rpm)[7]. The Flywheel rim diameter is found to $82 \mathrm{~cm}$ which gives the weight of flywheel as $150 \mathrm{Kg}$ and $266 \mathrm{Kg}$ for $240 \mathrm{rpm}$ and $180 \mathrm{rpm}$ respectively. Hence Modak J.P.(1987) suggested the flywheel with $150 \mathrm{Kg} @ 240 \mathrm{rpm}$ [7]. Further Modak J.P.(1987) has also found that driving torque of pedal is unaffected by increasing flywheel moment of inertia and stores same energy for same frequency of thigh oscillation [7].

\subsection{Gear ratio}

Modak J.P. (1987) suggested the value of gear ratio as 4:1 so as to reduce the effect of jerk induced at process unit shaft as result of energy or momentum exchange during the clutch engagement. If lower value of gear ratio is to be used then flywheel speed should be maintained higher than $240 \mathrm{rpm}$ [7].

\section{CAD MODELING OF THE SYSTEM.}

The CAD modeling of the proposed system for multiple rider is done by using the software Solid edge.

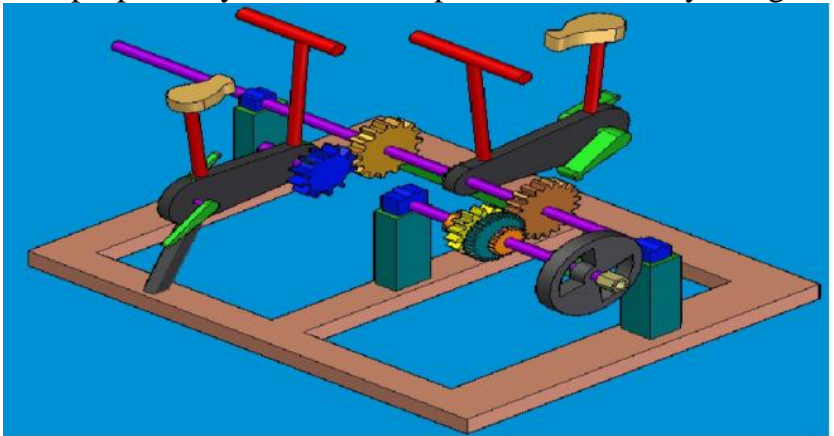

Fig3-CAD mdel of HPFM using solid edge.

This CAD model can be used for the various purposes such as simulation, stress analysis, ergonomic analysis etc. and consequently contributes in the performance optimization of the HPFM.

\section{Conclusion}

Due to ever increasing energy crises the use of human energized machines are increasing day by day. The number of advantages are associated with this such as unavailability of power specially in rural side of India, less skilled operators, unemployment, bicycle excersing etc . Hence human power machines seems to have great future ahead. In this paper the HPFM with multiple rider system is proposed. The actual model is under development. The CAD model of HPFM in solid edge is developed which can be used for various computational analysis.

\section{Journal Papers:}

\section{REFERENCES.}

[1]. Modak J.P, Bapat A.R. "Various efficiencies of human powered flywheel motor" Human power number volume 54;pp21-23

[2]. Modak J.P, Kazi Z S “ design and development of human energised chaff cutter” [New York Science Journal 2010;3 (4):104108].(ISSN:1554-0200).

[3]. Modak J.P , Moghe S.D "Design and development of human powered machine for the manufacture of lime flyash sand bricks" Human power; volume 13 num-ber2;1998;pp3-7.

[4]. Modak J.P, Bapat A.R. “ Improvement in experimental setup for establishing generalized experimental model of various dynamic responses for A manually energised flywheel motor"

[5]. Modak J.P ,Bapat A.R.. " Formulation of generalized experimental model for manually driven flywheel motor and its optimization" Applied ergonom-ics;1994; volume 25; number2; pp 119-122.

\section{Proceedings Papers:}

[6]. Modak J.P "Bicycle and its kinematics and modifications". National conference mach Mech; February 1985;pp5-11.

[7]. Modak J.P. , Chandurkar K.C., Singh M.P, Yadpana-war A.G "Experimental verification of various bi-cycle drive mechanism part1" Proceedings of AMSE conference modeling and simulation Karisurhe west Germeny, july 20-22 1987;pp139-160.

[8]. Modak J.P "General consideration of mechanical design of A manually driven process machine” NA-COMM; $1987 ;$;p 13-17. 